๑ Laboratorium: журнал социальных исследований. 2020. 12(1):195-198

DOI: $10.25285 / 2078-1938-2020-12-1-195-198$

\title{
Влада Баранова
}

Laura Assmuth, Marina Hakkarainen, Aija Lulle, and Pihla Maria Siim, eds. Translocal Childhoods and Family Mobility in East and North Europe. London: Palgrave Macmillan, 2018. 270 pp. ISBN 978-3-319-89734-9.

Влада Баранова, департамент социологии, Национальный исследовательский университет «Высшая школа экономики» (Санкт-Петербург), Институт лингвистических исследований РАН. Адрес для переписки: НИУ ВШЭ, ул. Седова, 55, корп. 2, Санкт-Петербург, 192148, Россия. vbaranova@hse.ru.

Внимание не только к экономически активным молодым участникам миграционного процесса, но и к тем, чьи жизненные траектории меняются под влиянием собственной или семейной мобильности, в последние годы усиливается, и, как отмечает Жаклин Баба в исследованиях миграции, «возраст становится значимой переменной» (Bhabha 2018:1). Можно отметить, например, относительно недавний сборник о детях мигрантов в рамках публикаций сети исследователей миграции IMISCOE (Seeberg and Goździak 2016) или книгу о том, как вовлечены в миграцию старшее поколение и пожилые в Перу (Horn 2019). При этом для подобного рода публикаций, к которым относится и рецензируемая книга, характерно смещение фокуса с адаптации или процесса «взросления» как постепенного включения в принимающее общество (такой акцент характерен для классических работ о детях в миграции, например, Zhou and Bankston 1998) на само мобильное детство и опыт ребенка, растущего в перемещении между странами и регионами.

Подобный взгляд встроен в теоретическую рамку транснационализма - подхода, концентрирующего внимание на самом переходном состоянии мигранта, являющегося частью социальной и экономической жизни в нескольких сообществах одновременно и привносящего что-то новое в каждое из них (Glick Schiller, Basch, and Blanc 1995). Однако авторы, по крайней мере в заглавии, отказываются от понятий «миграция», «(им)мигранты» и предлагают взамен понятия, связанные с мобильностью. Как отмечается в коллективном введении («Children in Translocal Families»), перемещение в пространстве важно само по себе - не только в контексте пересечения государственных границ и смены языка и других ориентиров. В качестве терминологического и одновременно теоретического решения авторы используют понятия «транслокальность» и «транслокальное детство» (вместо более привычного «транснациональное»). Сам термин не является инновацией авторов и в последнее время иногда встречается в разных работах о миграции (например, Greiner and Sakdapolrak 2013), однако, как кажется, остается все-таки достаточно размытым понятием. Что не войдет в понимание транслокального? Будет ли транслокальностью сезонная миграция? Кажется, да - поскольку возможно привнесение нового опыта из мегаполиса в сельскую локацию. А работа в течение недели в Москве с возращением на выходные к семье во Владимир или Нижний Новгород? Строго говоря, подразумеваемая новым термином связь транснационализма с нацией несколько упрощает подход: одна из его основательниц, 
Нина Глик Шиллер, призывала к рассмотрению разных типов локальности и отмечала, что она и соавторы хотели как раз отойти от понимания национального государства как «основной единицы анализа» (Glick Schiller 2007:17; обсуждение разных терминов и объема понятий: De Jong and Dennecker 2018). Рецензируемая книга продолжает эти дискуссии и вносит теоретический вклад в транс-подходы, хотя и не дает однозначных ответов.

Для рецензируемой книги важно рассмотрение детства в миграции в контексте Восточной Европы: исследовательский проект и настоящее издание объединяет исследователей из Восточной и Северной Европы, и основная часть героев дети, приехавшие из Восточной Европы (как правило, Латвия, Россия, Эстония) в Финляндию или, в отдельных случаях, другие страны. Ареальный подход позволяет учесть и специфику региона, в том числе и климатическую, и социальное сходство повседневных практик в постсоциалистических локациях. Герои этой книги переезжают сравнительно недалеко, имеют возможность регулярно ездить в страну исхода, по большей части не относятся к числу видимых меньшинств, не меняют климат, а переход от одной системы социальных отношений и экономических практик к другой не столь разителен, как в случае, например, миграции из стран Ближнего Востока или Африки.

Все, кто когда-либо сталкивался с детскими нарративами, знают, насколько они фрагментарны, контекстно обусловлены, изменчивы и так далее - то есть тесно связаны с особенностями запоминания и проговаривания опыта у ребенка. Авторы обращаются, помимо интервью с детьми и родителями и наблюдений, к целой серии интересных методов, позволяющих воссоздать переживания ребенка: кукольному театру, прорисовыванию опыта, записыванию и прочтению вслух истории респондента (с. 21-22). Некоторые детские рисунки включены в книгу (например, с. 206), а каждый раздел открывает специальный рисунок художника, воплощающий один из аспектов детских историй, и история-виньетка.

Принцип организации разделов показывает, что перед нами не сборник статей, а то, что в отечественной традиции называют «коллективная монография», то есть книга, объединенная общим подходом и предполагающая существенную степень связанности разделов. Это единство прослеживается в композициональной перекличке первого текста и заключения («Путешествие начинается» - «Путешествие продолжается»), а названия отдельных глав указывают прежде всего на те или иные аспекты транслокального детства, а не на особенности конкретного кейса - этнической группы, страны происхождения или проживания (за исключением разве что раздела об особенностях полевой работы с цыганскими семьями). Таким образом, хотя главы книги не претендуют на полноту освещения транслокального детства, они могут быть прочитаны как единый нарратив о перемещении и мобильном детстве через анализ телесности, материального мира, именника, летней жизни в деревне у бабушки, экономических отношений, школы и образования и возраста. Возможно поэтому читателю может показаться, что немного теряется специфика конкретных кейсов, этнических или локальных, хотя взамен мы можем наблюдать единство этого опыта и сходство контекстов. 
Главы о дороге детей в Эстонию или Латвию Агнесы Банковской (Agnese Bankovska) и Пихлы Сиим (Pichla Maria Siim) и глава Айи Лулле (Aija Lulle) и Пихлы Сиим о лете, проведенном у родственников, примыкают друг к другу и посвящены тому, как дети воспринимают материальную сторону перемещения, дороги, нового пространства и знаковых моментов одной и другой локальности. Тему материальной стороны миграции продолжает глава Марины Хаккарайнен (Marina Hakkarainen) о русскоязычных детях в Финляндии: автор показывает, как дети и подростки осмысляют новый опыт через вещную сторону и включаются в практики потребления в новой стране. Хаккарайнен акцентирует взгляд на детей как на участников экономического процесса, подобный подход перекликается с другими разделами книги, посвященными субъектности ребенка в миграции.

Глава Марты Балод (Marta Balode) и Айи Лулле о детских именах, на мой взгляд, одна из самых интересных в книге. Авторы анализируют выбор имени для ребенка в смешанном браке (матери из Латвии живут в Финляндии и Англии), а также рассматривают взаимодействие обладателя иноязычного личного имени с окружением с точки зрения принятия/непринятия имени, стремления к мимикрии, выражающейся в поиске «нейтрального» интернационального имени. Имянаречение в этих интервью оказывается в первую очередь вопросом семейного контроля со стороны одного из родителей или родственников при выборе этнических имен, которые будут указывать на чуждость ребенка в новой стране или при возвращении в Латвию.

Две главы посвящены наиболее уязвимой группе мигрантов - цыганам. Айри Маркканен (Airi Markkanen) рассматривает особенности полевой работы с рома, а Анка Энахе (Anca Enache) в фантастически интересной главе о цыганах-рома из Румынии, живущих в Финляндии, исследует отношения внутри возрастных групп, степень ответственности детей разного возраста и другие аспекты, формирующие agency детей-цыган.

Два текста - Лауры Асмут (Laura Assmuth) и Пихлы Сиим и глава Марины Хаккарайнен «Становясь лучше через образование» - обращаются к институциональному контексту на примере детей из разных стран. Именно школа является тем образом государства, с которым сталкивается ребенок в новой стране в первую очередь. Это также тот контекст, как отмечают Асмут и Сиим (с. 163-164), где происходят переговоры внутри семьи и сталкиваются разные понимания образования у разных поколений мобильной семьи. Школа важна и для осмысления этапов взросления и возраста ребенка, к которым обращается Лулле в главе 10 «Возраст имеет значение: встреча с динамикой детской агентивности от колыбели до проявляющейся взрослости».

В заключение хочется отметить, что путешествие только начинается и ни одна из поднятых в книге тем не закрыта. Наоборот, исследователи детства и миграции могут увидеть важные вопросы, к которым можно обратиться и на материале других групп в другом контексте. Одно из самых важных достоинств этой книги, на мой взгляд, - это бережный подход и внимание к голосам респондентов. Субъектность детей и признание значимости их опыта со стороны исследователей, готовых быть медиаторами в рассказе о нем, показывает, как бережно можно работать 
с детским нарративом о мобильности. Подобный подход важен и для разговора о детях в миграции в русскоязычном социологическом и антропологическом профессиональном сообществе, не всегда внимательном к тем, кого изучает. Отдельно хочется отметить, что книга написана простым языком и включает много выдержек из полевых дневников и интервью, что создает ощущение сопричастности ее героям. Это не только делает ее прекрасным исследованием по антропологии миграции, но, как пишут в аннотациях, адресует всем читателям, интересующимся мобильностью.

\section{СПИСОК ЛИТЕРАТУРЫ}

Bhabha, Jacqueline. 2018. "Introduction." Pp. 1-6 in Research Handbook on Child Migration, ed. by Jacqueline Bhabha, Jyothi Kanics, and Daniel Senovilla Hernández. Cheltenham, UK: Edward Elgar.

De Jong, Sara, and Petra Dennecker. 2018. "Connecting and Confronting Transnationalism: Bridging Concepts and Moving Critique." Identities 25(5):493-506. doi:10.1080/1070289X.2018.1507 962.

Glick Schiller, Nina. 2007. "Beyond the Nation-State and Its Units of Analysis: Towards a New Research Agenda for Migration Studies. Essentials of Migration Theory." Working Paper 33, COMCAD - Center on Migration, Citizenship and Development, Bielefeld.

Glick Schiller, Nina, Linda Basch, and Cristina Szanton Blanc. 1995. "From Immigrant to Transmigrant: Theorizing Transnational Migration." Anthropological Quarterly 68(1):48-63. doi: $10.2307 / 3317464$.

Greiner, Clemens, and Patrick Sakdapolrak. 2013. “Translocality: Concepts, Applications and Emerging Research Perspectives." Geography Compass 7(5):373-384. doi:10.1111/gec3.12048.

Horn, Vincent. 2019. Aging within Transnational Families: The Case of Older Peruvians. London: Anthem Press.

Seeberg, Marie Louise, and Elżbieta M. Goździak, eds. 2016. Contested Childhoods: Growing Up in Migrancy: Migration, Governance, Identities. Cham, Switzerland: Springer.

Zhou, Min, and Carl L. Bankston. 1998. Growing Up American: How Vietnamese Children Adapt to Life in the United States. New York: Russell Sage Foundation. 